\title{
Association of glycemic index and glycemic load with risk of incident coronary heart disease among Whites and African Americans with and without type 2 diabetes: The Atherosclerosis Risk in Communities Study
}

\author{
Dale Hardy, Ph.D. R.D. C.D.E. ${ }^{1}$, Deanna M. Hoelscher, Ph.D. R.D. C.N.S. ${ }^{2}$, Corinne Aragaki, \\ Ph.D. ${ }^{1}$, June Stevens, Ph.D. ${ }^{3}$, Lyn M. Steffen, Ph.D. R.D. ${ }^{4}$, James S. Pankow, Ph.D. ${ }^{4}$, and \\ Eric Boerwinkle, Ph.D. ${ }^{1,5}$ \\ ${ }^{1}$ Division of Epidemiology, University of Texas School of Public Health, Houston, TX 77030 \\ ${ }^{2}$ Michael \& Susan Dell Center for Advancement of Healthy Living, University of Texas School of \\ Public Health, Austin, TX 78701 \\ ${ }^{3}$ School of Public Health, University of North Carolina at Chapel Hill, Chapel Hill, NC 27514 \\ ${ }^{4}$ Division of Epidemiology and Community Health, School of Public Health, University of \\ Minnesota, MN 55454 \\ ${ }^{5}$ Human Genetics Center, University of Texas School of Public Health, Houston, TX 77030
}

\begin{abstract}
Purpose-This study examined whether high glycemic index (GI) and glycemic load (GL) diets are associated with increased risk of developing CHD in Whites and African Americans with and without type 2 diabetes.

Methods-Data on 13,051 individuals aged 45-64 years from the Atherosclerosis Risk in Communities (ARIC) study were analyzed. The ARIC food frequency questionnaire baseline data provided GI and GL indices. A propensity score was created to estimate the effect of an individual's covariates on energy-adjusted GI or GL. During a maximum of 17 years of follow-up, 1,683 cases of CHD (371 with diabetes and 1,312 without diabetes) were recorded.

Results-For every 5-units increase in GI, there was a 1.16-fold (95\% CI:1.01, 1.33) increased risk of incident CHD in African Americans. For every 30-units increase in GL, there was a 1.11fold (95\% CI:1.01, 1.21) increased risk of incident CHD in Whites. High GL was an especially important CHD risk factor for Whites without diabetes (per 30-units increase) (HR=1.14; 95\% CI: $1.02,1.26)$. However, these relationships were not seen in individuals with diabetes.
\end{abstract}

Conclusions-Nutritional advice to reduce the GI and GL in diets of African Americans, and Whites (without diabetes) may play a role in reducing CHD risk.

(C) 2010 Elsevier Inc. All rights reserved.

Send correspondence requests to: Eric Boerwinkle, Ph.D., Human Genetics Center, RAS-E447, University of Texas Health Science Center at Houston, PO Box 20186, Houston, TX 77225, Phone: (713) 500-9816, Fax: (713) 500-0900, Eric.Boerwinkle@uth.tmc.edu. Publisher's Disclaimer: This is a PDF file of an unedited manuscript that has been accepted for publication. As a service to our customers we are providing this early version of the manuscript. The manuscript will undergo copyediting, typesetting, and review of the resulting proof before it is published in its final citable form. Please note that during the production process errors may be discovered which could affect the content, and all legal disclaimers that apply to the journal pertain. 


\section{Keywords}

Coronary heart disease; glycemic index; glycemic load; type 2 diabetes; race; Whites; African Americans

\section{Introduction}

Coronary heart disease (CHD) is the most common cause of death in the United States. ${ }^{1}$ Costs associated with CHD, including healthcare expenditures, medications, and lost productivity from death and disability, are estimated to be $\$ 316.4$ billion in $2010 .{ }^{1}$ Despite advances in medical treatments, most long-term solutions to this epidemic include prevention advice regarding diet and lifestyle choices. ${ }^{2}$

It has been recognized that diet plays a major role in decreasing risk of CHD by affecting risk factors such as blood glucose, blood lipids, and blood pressure. The gel forming properties of viscous soluble fibers present in whole grains and legumes attenuate the rise in blood glucose, lipids, and insulin levels. ${ }^{3,4}$ Viscous soluble fiber foods have a low glycemic index (GI) due to their ability to expand and promote prolonged digestion in the small intestines to enhance satiation. ${ }^{3,4}$ The consumption of these foods has been demonstrated to improve blood glucose in individuals with and without diabetes and to decrease risks for mortality and incident CHD. ${ }^{3-5}$ GI and glycemic load (GL) are used to evaluate the glycemic properties of the diet. Low GI and GL diets are commonly promoted, although a causal association and the efficacy of dietary intervention targeting GI or GL on CHD risk or mortality prevention is unproven in clinical trials. Both high GI and GL diets have been shown to predict risk of developing $\mathrm{CHD},{ }^{6-8}$ although some studies have shown inconsistent results.., 10

Of relevance is the necessity to use GI and GL in nutritional counseling and in the selection of foods to prevent and treat chronic diseases, such as diabetes and CHD. Of special concern is the application of GI and GL in the diets of individuals with diabetes and in at-risk minority groups such as African Americans because of their increase risk for obesity, hypertension, and type 2 diabetes. Although multiple studies have investigated the association between a high GI or a high GL diet and risk of CHD in Whites, ${ }^{7-11}$ no study has investigated this association in African Americans. The purpose of this study is to determine the association between high GI or high GL diets and the risk of developing CHD among Whites and African Americans with and without type 2 diabetes in the Atherosclerosis Risk in Communities (ARIC) study.

\section{Research Design and Methods}

The ARIC study, established in 1987, is a large scale, ongoing prospective cohort study of 15,792 individuals aged 45 to 64 years old at baseline, sponsored by the National Heart and Lung and Blood Institute with a total of four visits from 1987 to 1989 until 1996 to 1998. There was a $60 \%$ overall participation rate, including $42 \%$ and $49 \%$ of eligible African American men and women, and $67 \%$ and $68 \%$ of eligible white men and women respectively. ${ }^{12}$ Further design and sampling methods are explained elsewhere. ${ }^{13}$

Participants who are of race groups besides African American and White were excluded ( $\mathrm{n}=$ 48) from this analysis, as well as African Americans from Minnesota $(n=22)$, and Maryland $(n=33)$ because of too few individuals to support race and field center-specific analyses. From this sample, participants with pre-existing CHD $(n=763)$ and stroke $(n=336)$ at baseline, individuals with missing diagnostic information for type 2 diabetes $(n=125)$, 
prevalent CHD ( $\mathrm{n}=316)$ and stroke $(\mathrm{n}=347)$, together with individuals with missing covariate data $(\mathrm{n}=481)$ were also excluded. Participants with missing nutritional information $(\mathrm{n}=10)$, and those with nutritional intake $<596 \mathrm{kcal}$ or $>3125 \mathrm{kcal}$ for women $(\mathrm{n}=145)$ and $<697 \mathrm{kcal}$ or $>3763$ for men $(\mathrm{n}=115)$ were also excluded in order to eliminate implausible nutrient intake values. These cutoff points approximated the lower and upper $1 \%$ of the energy distribution. The final study sample consisted of 13,051 individuals of whom 9,685 (74.2\%) were Whites, and 3,366 (25.8\%) were African Americans. All participants signed an informed consent and the Institutional Review Boards approved of the study prior to implementation.

\section{Study examination and measurements}

Incident CHD (the primary outcome variable) was defined as a first CHD event occurring after the date of the baseline physical exam. CHD was identified as a confirmed CHD death, fatal and non-fatal myocardial infarction, silent myocardial infarction identified by blinded side-by-side electrocardiograph (ECG) readings read by two technicians independently, coronary artery bypass graph surgery, and/or coronary revascularization. Fatal myocardial infarction was defined as history of chest pains within 72 hours of death, history of chronic ischemic heart disease such as definite or probable myocardial infarction, coronary insufficiency, or angina pectoris in the absence of valvular disease or non-ischemic cardiomyopathy. CHD events were updated at each visit and yearly telephone follow-up by evaluating discharge hospital lists, death certificates from state vital statistics offices, nextto-kin interviews, and physician-completed questionnaires.

Participants were defined as having diabetes at baseline if blood glucose was $\geq 126 \mathrm{mg} / \mathrm{dl}$ after at least eight hours of fasting time or had a non-fasting blood glucose $\geq 200 \mathrm{mg} / \mathrm{dl}$ using venous sampling, or if they reported being diagnosed with diabetes by a physician, or reported taking medications for diabetes within two weeks preceding their examination.

Covariates considered in the study were established risk factors from the Framingham Heart study and known risk factors for CHD in ARIC. ${ }^{14,15}$ These risk factors included race, sex, age, anti-hypertensive medications (yes/no), and cigarette smoking (current/former/ever), self-reported at the time of the household interview. Body mass index (BMI) and systolic blood pressure (SBP) were measured using standard ARIC protocol. Fasting total and HDL cholesterol were measured on a Cobas-Bio analyzer using standard enzymatic methods. ${ }^{16}$ Fasting blood glucose was measured using a modified Hexokinase/glucose 6-phosphate dehydrogenase method. ${ }^{16}$ Keys dietary lipid scores were calculated using polyunsaturated fat, dietary cholesterol, and energy. ${ }^{17}$ Additional variables included a sports activity index, education level ( $\leq 11 / 12-16 / 17-21$ years), and total calories (because of its confounded relationship with GI or GL and CHD risk ${ }^{18)}$.

\section{Calculation of glycemic index and glycemic load}

GI and GL (exposure variables), together with total calories and Keys score ${ }^{17}$ were derived from a 66-item semiquantitative food frequency questionnaire (FFQ) collected at the time of the baseline interview. This instrument was a modified version of the 61-item FFQ design and validated by Willett et al. ${ }^{19}$ GI in this study refers to the ranking of the postprandial blood glucose response when 50 grams of the available carbohydrate in a food is consumed as compared to 50 grams of white bread (the reference food). ${ }^{20,21} \mathrm{GI}$ is expressed as a percentage and represents the relative rate of glucose appearance into the blood compared to white bread. GL calculated from the GI, reflects the whole day's intake on expected postprandial blood glucose changes. It represents the type of carbohydrate eaten together with the quantity of food consumed. Consequently, GL can be a better predictor of postprandial response to carbohydrate foods and insulin secretion than GI. ${ }^{20,21}$ The mean 
dietary GL for each participant was calculated by adding the products of carbohydrate content per serving of each food times the average number of servings of that food per day times the GI for that food. GI for each individual was computed by dividing the GL by the total carbohydrate intake per day. ${ }^{20,21}$ GI and GL were transformed to their energy-adjusted forms using the residual method as described by Willett. ${ }^{18}$ This process of energyadjustment holds total caloric intake constant in the study population, while the varied quantity of GI or GL is compared between groups.

\section{Statistical Analysis}

Baseline data from ARIC from 1987 to 1989 with follow-up for incident CHD events through 2004 were used for the analyses presented here. Person-time follow-up (in months) were calculated from the date of the baseline physical exam which was also the date the FFQ interview, to the date of the CHD event or censoring (including deaths from other causes or lost to follow-up) on December 31, 2004. Analyses were conducted using STATA, version 11.0 (STATACORP, College Station, Tex).

Cox proportional hazards regression analyses were used to evaluate the relationship between GI or GL and risk of developing CHD. In order to express the relationship between GI or GL in meaningful units, hazard ratios from the Cox proportional hazards regression analyses were calculated to project a change in GI or GL levels equal to the interquartile range (IQR) difference of GI (4.9 rounded to 5) and GL (29.9 rounded to 30). To control for confounding of the association between GL or GI and CHD, the method of a propensity score was used. A propensity score is the predicted value of consuming a specific level of GI or GL taking into account an individual's observed covariates. ${ }^{22}$ The propensity score summarizes the effect of the covariates on energy-adjusted GI or GL. The advantages of the propensity score method compared to the traditional multivariable adjustment methods is in correction for residual confounding and decrease in selection bias. ${ }^{22}$

Propensity scores were created for Whites and African Americans by diabetes status separately. In brief, propensity scores were constructed by fitting a linear regression model to estimate the effects of age, sex, BMI, SBP, total cholesterol, HDL cholesterol, antihypertensive medications, cigarette smoking, sports activity index, Keys dietary score, fasting blood glucose, and total calories on energy-adjusted GI or GL. The predicted values were then created and these were designated as the propensity scores which were used in the survival analysis model as the only covariate with energy-adjusted GI or GL as the exposure variable. ${ }^{23}$ Because the propensity score method is not widely used in nutritional research, we also used more traditional multivariable methods and similar effect size estimates of GI and GL on CHD risk were observed, but $\mathrm{p}$ values tended to vary (data not shown).

\section{Results}

The study sample consisted of 13,051 individuals aged 45 to 64 years old (mean age $=54$ years) free of CHD at baseline. During a maximum of 17 years of follow-up, the study recorded 1,683 CHD events (371 with diabetes and 1,312 without diabetes) of which 569 were CHD deaths. At baseline, the study sample consisted of $7.9 \%(\mathrm{n}=763)$ Whites and $18.3 \%(\mathrm{n}=615)$ African Americans with diabetes. Of the 11,673 participants without diabetes at baseline $11.6 \%(\mathrm{n}=1,347$, i.e. $72.0 \%$ Whites, $27.9 \%$ African Americans without diabetes) had high fasting blood glucose $(\mathrm{FBG})>110 \mathrm{mg} / \mathrm{dl}$. Of the 1,378 subjects who reported having diabetes at baseline, only $9.4 \%(\mathrm{n}=130$, i.e. $53.8 \%$ Whites, $46.2 \%$ African Americans with diabetes) had normal FBG levels from 70 to $110 \mathrm{mg} / \mathrm{dl}$.

The mean energy-adjusted GI was $52.4(\mathrm{SD}=4.4)$, with an IQR range of 50.3 to 55.2. The mean energy-adjusted GL was $103.6(\mathrm{SD}=23.3)$ with $\mathrm{IQR} 88.4$ to 118.3. Mean energy- 
adjusted GI values for African Americans compared to Whites were 53.7 versus 52.0 with IQR 51.7 to 56.3 versus IQR of 49.8 to 54.8 , respectively. Similarly, the mean energyadjusted GL values for African Americans compared to Whites were 108.0 versus 102.1 with IQR of 93.0 to 122.6 versus 87.0 to 116.7 , respectively.

All descriptive characteristics of the sample were significantly different for Whites and African Americans between persons with and without diabetes, except for Whites where energy-adjusted GI, total calories, and the propensity score for energy-adjusted GI was not statistically different by diabetes status (table 1).

After adjusting for traditional risk factors and risk factors found in ARIC for CHD using a propensity score, energy-adjusted GI was significantly associated with incident CHD in African Americans and energy-adjusted GL was significantly associated with incident CHD in Whites (table 2). With every increase in 5-units of energy-adjusted GI, African Americans had 1.16-fold (95\% CI:1.01, 1.33) increased risk of CHD. For every 30-units increase in energy-adjusted GL, Whites were predicted to have a 1.11-fold (95\% CI:1.01, 1.21) increase in CHD risk.

Stratified analyses were performed to investigate whether energy-adjusted GI or GL at baseline was associated with incident CHD in each race group and by diabetes status. Whites without diabetes had a 1.14-fold $(95 \%$ CI:1.02, 1.26) elevation in risk of CHD (table 3) for every increase in 30-units of energy-adjusted GL, which remained statistically significant after correcting for multiple comparisons using Bonferonni adjustment at $\mathrm{p}<$ 0.025 . However, these relationships were not seen in individuals with diabetes.

\section{Discussion}

In this middle-aged sample with 17 years of follow-up, we observed that a diet high in GI at baseline significantly increased the risk of CHD in African Americans and a high GL diet was associated with increased risk of CHD in Whites. In stratified analyses, the relationship between GL and incident CHD was more pronounced in Whites without diabetes.

The Nurses' Health Study found that White women without diabetes who consume a diet high in GL had increased risk of CHD. ${ }^{11}$ A population-based study of women without diabetes living in the Netherlands reported that a diet high in GI was associated with increased risk of CHD, but the results for GL were not significant. ${ }^{7}$ Likewise, an Italian case-control study reported similar non-significant findings for GL, but found an increased risk of acute MI in patients $\geq 60$ years old who consumed a high GI diet. ${ }^{8} \mathrm{~A}$ few studies reported null findings for high GI and GL diets and increased risk of CHD. The Zutphen Elderly Dutch study ${ }^{10}$ did not detect a significant relationship between GI or GL diets and increased risk of CHD. Similarly, a recent study on Swedish men confirmed these null findings. ${ }^{9}$

The hypothesis that high GI and GL diets exert their influence on insulin resistance by promoting hyperglycemia, hyperinsulinemia, high lipid levels, and decreasing insulin sensitivity is widely promulgated. ${ }^{20,24-26} \mathrm{GL}$ incorporates the effect of GI and the quantity of food eaten and hence can be used as a measure of insulin demand and insulin secretion. Foods such as potatoes and white bread have a high GI and are rapidly absorbed. Moreover, when these foods are eaten in moderate to large amounts they contribute to high GL which can increase insulin levels. ${ }^{25}$ In this study, GI was found to be associated with CHD in African Americans, and GL was associated with CHD in Whites. The significant associations for GL on CHD risk were seen in Whites without diabetes, but not in African Americans (with or without diabetes). GL is likely to be associated with more infusion of 
circulating glucose and higher postprandial insulin levels which can increase risk for CHD. $^{20}$

We attempted to control for bias in our study through a variety of methods. We did not adjust for fiber intake since soluble fiber is an integral part of both GI and GL; and conveys its effects on glycemia, in part, through this property. In other models for GI and GL that included fiber in the propensity score (data not shown), all analyses were not statistically significant in both Whites and African Americans. In this study, the mean fiber intake for Whites was 17.9 grams $(\mathrm{SD}=7.9)$ and that for African Americans was 16 grams $(\mathrm{SD}=7.9)$. We also did not explore other properties of the diet that may have influenced GI or GL on CHD risk, such as type of starch, water content, vitamin, mineral, or phytochemical content. Due to the prospective design of our study, recall bias was likely minimized. In addition, food models and recall aids were used during the FFQ interview which assisted in recall. We excluded subjects with missing nutritional information and subjects at the lower and upper $1 \%$ of energy distribution to help control for recall bias.

The disadvantages of this study include the 66-item FFQ which underestimates energy intake and potentially food intake due to the limited number of food items on the questionnaire. Also, the study used only baseline dietary intake to investigate the association on the development of CHD over 17 years of follow-up; dietary intake as well as the food supply may have changed over this long follow-up period. We also did not take into consideration participants who acquired diabetes during the years of follow-up or had changes in covariate values such as BMI, over time of study follow-up.

A concern in this study is the small sample size available for stratified analyses, such as by diabetes status. Among African Americans without diabetes, the hazard ratio (HR) for CHD associated with high GI (per 5-units increase) was 1.16, but did not reach statistical significance. Likewise, the HR for CHD associated with both GI and GL in African American participants with diabetes was greater than one and greater than that observed in Whites with diabetes, but again did not reach statistical significance. The frequency of CHD events in Whites and African Americans with diabetes was 32.5\% and 20.0\% respectively, which were higher than those without diabetes $(11.8 \%$ for Whites, $9.3 \%$ for African Americans). The interaction between GI or GL and diabetes status was not statistically significant. The sample size in the type 2 diabetes population within race groups was not large enough to bring about statistically significant effect estimates. Despite having a large sample size of African Americans in this study $(n=3,366)$ and 17 years of follow-up, it appears that even larger samples are necessary to resolve the question of the differential association of high GI and GL among African Americans with diabetes. The unique difference in our study from other studies on GI and GL is that we attempted to correct for selection bias and residual confounding using a propensity score which was not performed in the other studies.

According to the American Heart Association (AHA) a diet moderate in carbohydrate, low in sugars, saturated fat, trans fat, cholesterol, and high in fruits, vegetables, and whole grains is recommended for prevention of CHD. ${ }^{2}$ Foods recommended on the AHA diet tend to have low to moderate GI and GL values. In this study, we were able to show that high GI and GL diets were associated with increased risk in African Americans and Whites without diabetes respectively. Nutritional advice should focus on dietary patterns with the aim of reducing GI and GL in order to reduce CHD risk. The data presented here indicate that this is especially important in Whites without diabetes. However, the data do not support differential advice in African American individuals with diabetes compared to those without diabetes. Future studies should be carried-out in large samples of African Americans and in other racial groups where there are no available data. 


\section{Acknowledgments}

The Atherosclerosis Risk in Communities Study is carried out as a collaborative study supported by National Heart, Lung, and Blood Institute contracts N01-HC-55015, N01-HC-55016, N01-HC-55018, N01-HC-550'19, N01HC-55020, N01-HC-55021, and N01-HC-55022. The authors thank the staff and participants of the ARIC study for their important contributions.

\section{References}

1. Heart Disease Facts and Statistics. Atlanta, Georgia: Center for Disease Control and Prevention. Jan 25. 2010 Available from: http://www.cdc.gov/heartdisease/facts.htm

2. Lichtenstein AH, Appel LJ, Brands M, Carnethon M, Daniels S, et al. American Heart Association Nutrition Committee. Diet and lifestyle recommendations revision 2006: A scientific statement from the American Heart Association Nutrition Committee. Circulation. 2006; 114:82-896. [PubMed: 16785338]

3. Jenkins DJ, Kendall CW, Axelsen M, Augustin LS, Vuksan V. Viscous and nonviscous fibres, nonabsorbable and low glycaemic index carbohydrates, blood lipids and coronary heart disease. Curr Opin Lipidol. 2000; 11:49-56. [PubMed: 10750694]

4. Rizkalla SW, Bellisle F, Slama G. Health benefits of low glycaemic index foods, such as pulses, in diabetic patients and healthy individuals. Br J Nutr. 2002; 88(Suppl 3):S255-S262. [PubMed: 12498625]

5. Steffen LM, Jacobs DR Jr, Stevens J, Shahar E, Carithers T, Folsom AR. Associations of wholegrain, refined-grain, and fruit and vegetable consumption with risks of all-cause mortality and incident coronary artery disease and ischemic stroke: The Atherosclerosis Risk in Communities (ARIC) study. Am J Clin Nutr. 2003; 78:383-390. [PubMed: 12936919]

6. Liu S, Willett WC, Stampfer MJ, Hu FB, Franz M, Sampson L, et al. A prospective study of dietary glycemic load, carbohydrate intake, and risk of coronary heart disease in US women. Am J Clin Nutr. 2000; 71:1455-1461. [PubMed: 10837285]

7. Beulens JW, de Bruijne LM, Stolk RP, Peeters PH, Bots ML, Grobbee DE, et al. High dietary glycemic load and glycemic index increase risk of cardiovascular disease among middle-aged women: A population-based follow-up study. J Am Coll Cardiol. 2007; 50:14-21. [PubMed: 17601539]

8. Tavani A, Bosetti C, Negri E, Augustin LS, Jenkins DJ, La Vecchia C. Carbohydrates, dietary glycaemic load and glycaemic index, and risk of acute myocardial infarction. Heart. 2003; 89:722726. [PubMed: 12807839]

9. Levitan EB, Mittleman MA, Hakansson N, Wolk A. Dietary glycemic index, dietary glycemic load, and cardiovascular disease in middle-aged and older Swedish men. Am J Clin Nutr. 2007; 85:15211526. [PubMed: 17556687]

10. van Dam RM, Visscher AW, Feskens EJ, Verhoef P, Kromhout D. Dietary glycemic index in relation to metabolic risk factors and incidence of coronary heart disease: The Zutphen Elderly study. Eur J Clin Nutr. 2000; 54:726-731. [PubMed: 11002385]

11. Liu P, Perry T, Monro JA. Glycaemic glucose equivalent: Validation as a predictor of the relative glycaemic effect of foods. Eur J Clin Nutr. 2003; 57:1141-1149. [PubMed: 12947434]

12. Jackson R, Chambless LE, Yang K, Byrne T, Watson R, Folsom A, et al. Differences between respondents and nonrespondents in a multicenter community-based study vary by gender ethnicity. The Atherosclerosis Risk in Communities (ARIC) study investigators. J Clin Epidemiol. 1996; 49:1441-1446. [PubMed: 8970495]

13. The Atherosclerosis Risk in Communities (ARIC) study: Design and objectives. The ARIC investigators. Am J Epidemiol. 1989; 129:687-702. [PubMed: 2646917]

14. Gordon T, Kannel WB. Multiple risk functions for predicting coronary heart disease: The concept, accuracy, and application. Am Heart J. 1982; 103:1031-1039. [PubMed: 7044082]

15. Chambless LE, Folsom AR, Sharrett AR, Sorlie P, Couper D, Szklo M, et al. Coronary heart disease risk prediction in the Atherosclerosis Risk in Communities (ARIC) study. J Clin Epidemiol. 2003; 56:880-890. [PubMed: 14505774] 
16. National Heart Lung, and Blood Institute. Atherosclerosis Risk in Communities (ARIC) study. Operations manual no 8: Lipid and lipoprotein determinations version 1.0. 1987

17. Keys A, Anderson JT, Grande F. Prediction of serum-cholesterol responses of man to changes in fats in the diet. Lancet. 1957; 273:959-966. [PubMed: 13482259]

18. Willett, W. Nutritional Epidemiology. 2nd. New York: Oxford University Press; 1998.

19. Willett WC, Sampson L, Stampfer MJ, Rosner B, Bain C, Witschi J, et al. Reproducibility and validity of a semiquantitative food frequency questionnaire. Am J Epidemiol. 1985; 122:51-65. [PubMed: 4014201]

20. Bell SJ, Sears B. Low-glycemic-load diets: Impact on obesity and chronic diseases. Critical Reviews in Food Science \& Nutrition. 2003; 43:357-377. [PubMed: 12940416]

21. Monro JA, Shaw M. Glycemic impact, glycemic glucose equivalents, glycemic index, and glycemic load: Definitions, distinctions, and implications. Am J Clin Nutr. 2008; 87:237S-243S. [PubMed: 18175763]

22. Rosenbaum PR, Rubin DB. The central role of the propensity score in observational studies for causal effects. Biometrika. 1983; 70:41-55.

23. Robins JM, Mark SD, Newey WK. Estimating exposure effects by modelling the expectation of exposure conditional on confounders. Biometrics. 1992; 48:479-495. [PubMed: 1637973]

24. Brand-Miller JC. Glycemic load and chronic disease. Nutr Rev. 2003; 61:S49-S55. [PubMed: 12828192]

25. Dickinson S, Brand-Miller J. Glycemic index, postprandial glycemia and cardiovascular disease. Curr Opin Lipidol. 2005; 16:69-75. [PubMed: 15650566]

26. Augustin LS, Franceschi S, Jenkins DJ, Kendall CW, La Vecchia C. Glycemic index in chronic disease: A review. Eur J Clin Nutr. 2002; 56:1049-1071. [PubMed: 12428171]

\section{List of Abbreviations and Acronyms}

$\begin{array}{ll}\text { ARIC } & \text { Atherosclerosis Risk in Communities } \\ \text { AHA } & \text { American Heart Association } \\ \text { GI } & \text { glycemic index } \\ \text { GL } & \text { glycemic load } \\ \text { CHD } & \text { coronary heart disease } \\ \text { ECG } & \text { electrocardiograph } \\ \text { SBP } & \text { systolic blood pressure } \\ \text { BMI } & \text { body mass index } \\ \text { HDL } & \text { high density lipoprotein } \\ \text { FFQ } & \text { food frequency questionnaire } \\ \text { IQR } & \text { interquartile range }\end{array}$


Table 1

Mean or percent (\%) baseline characteristics of all subjects (Whites and African Americans) by diabetes status in ARIC

\begin{tabular}{|c|c|c|c|c|}
\hline & \multicolumn{4}{|c|}{ Mean or Column \% } \\
\hline & \multicolumn{2}{|c|}{ Whites } & \multicolumn{2}{|c|}{ African Americans } \\
\hline \multirow[b]{2}{*}{ Characteristic } & \multicolumn{2}{|c|}{ Diabetes } & \multicolumn{2}{|c|}{ Diabetes } \\
\hline & $\begin{array}{c}\text { No } \\
(n=8922)\end{array}$ & $\underset{(n=763)}{\text { Yes }}$ & $\begin{array}{c}\text { No } \\
(\mathrm{n}=\mathbf{2 , 7 5 1})\end{array}$ & $\underset{\substack{\text { Yes } \\
(n=615)}}{ }$ \\
\hline Age (years) & 54.0 & 55.8 & 53.1 & 55.0 \\
\hline \multicolumn{5}{|l|}{$\operatorname{Sex}(\%)$} \\
\hline Male & 45.0 & 49.9 & 37.8 & 33.2 \\
\hline Female & 55.0 & 50.0 & 62.2 & 68.3 \\
\hline \multicolumn{5}{|l|}{ Educational level (\%) } \\
\hline High school ( $\leq 11$ years) & 14.6 & 24.3 & 38.2 & 52.0 \\
\hline Intermediate ( $12-16$ years) & 45.6 & 45.0 & 29.2 & 26.2 \\
\hline Advanced (17-21 years) & 39.7 & 30.7 & 32.6 & 21.8 \\
\hline $\mathrm{BMI}\left(\mathrm{kg} / \mathrm{mm}^{2}\right)$ & 26.6 & 30.4 & 29.1 & 31.8 \\
\hline Systolic blood pressure (mmHg) & 117.5 & 126.9 & 127.3 & 133.3 \\
\hline \multicolumn{5}{|l|}{ Smoking status (\%) } \\
\hline Current & 24.5 & 21.5 & 30.4 & 23.7 \\
\hline Former & 34.6 & 35.1 & 23.2 & 25.0 \\
\hline Never & 40.9 & 43.4 & 46.4 & 51.2 \\
\hline Fasting blood glucose (mg/dl) & 98.6 & 173.1 & 98.7 & 199.1 \\
\hline Total cholesterol (mg/dl) & 214.0 & 220.5 & 213.3 & 220.9 \\
\hline HDL cholesterol (mg/dl) & 52.0 & 42.6 & 56.6 & 49.5 \\
\hline \multicolumn{5}{|l|}{ Antihypertensive medications (\%) } \\
\hline No & 79.5 & 55.8 & 62.3 & 39.7 \\
\hline Yes & 20.5 & 44.2 & 37.7 & 60.3 \\
\hline Sports activity index & 2.6 & 2.4 & 2.2 & 2.1 \\
\hline Total calories (kcal) & 1625.2 & 1631.0 & 1606.9 & 1438.6 \\
\hline Keys score & 42.4 & 43.7 & 41.8 & 44.3 \\
\hline Energy-adjusted GI & 52.0 & 52.1 & 53.6 & 54.2 \\
\hline Energy-adjusted GL & 102.3 & 100.4 & 108.8 & 104.7 \\
\hline Propensity score: GI & 52.3 & 52.8 & 52.5 & 53.0 \\
\hline Propensity score: GL & 103.6 & 102.7 & 104.5 & 101.7 \\
\hline
\end{tabular}

$\mathrm{n}$, number of subjects in stratum; \%, percent in sub-sample; GI, glycemic index; GL, glycemic load; BMI, body mass index; HDL, high density lipoprotein cholesterol.

Tests based on oneway anova for differences among means of continuous variables (energy-adjusted GI, energy-adjusted GL, total calories, age, BMI, systolic blood pressure, fasting blood glucose, total cholesterol, HDL cholesterol, sports activity index, Keys score, propensity score: GI, and propensity score: GL) were all significant $(\mathrm{p}<0.05)$ between participants with and without diabetes for both race groups, except for energyadjusted GI, total calories, and propensity score: GL among Whites. Pearson's $\chi 2$ tests of hypothesis for independence to assess statistical significance in relationships between diabetes status and categorical variables among race groups showed that all were significant at $\mathrm{p}<0.05$ level, except for cigarette smoking among Whites. 


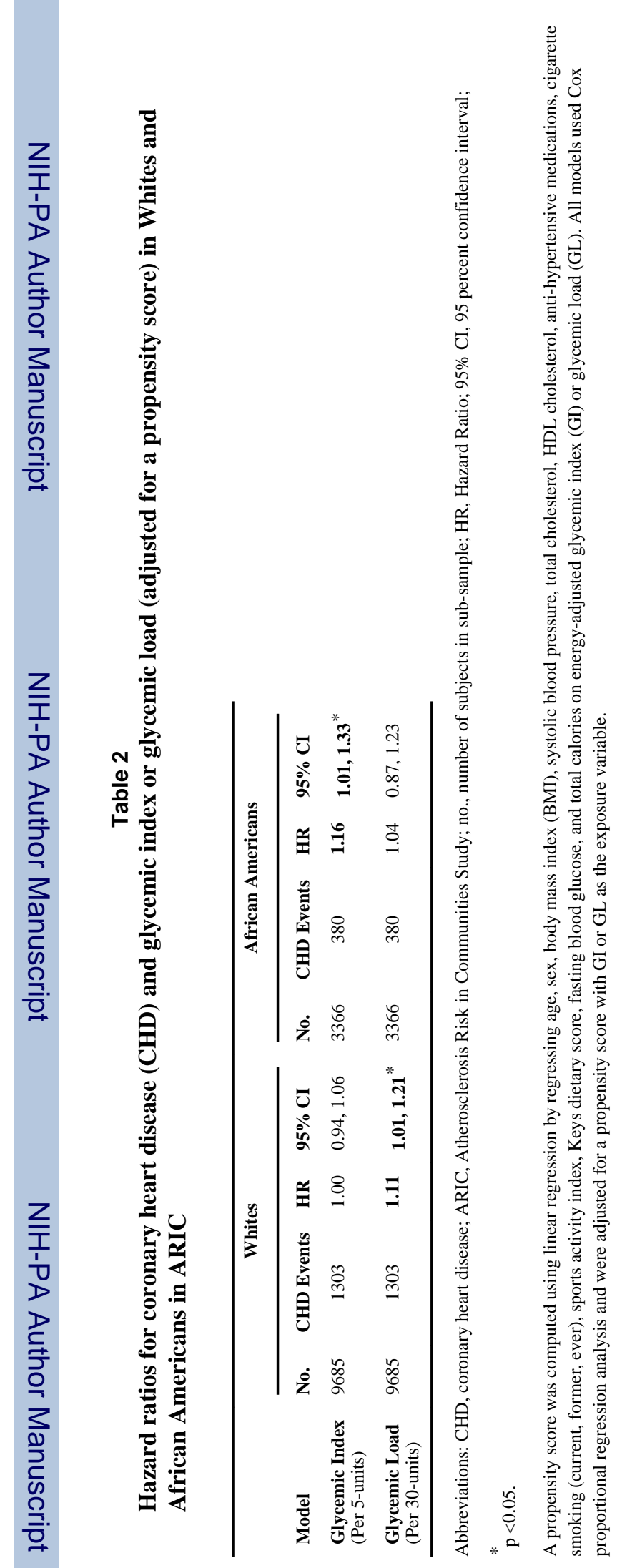

Ann Epidemiol. Author manuscript; available in PMC 2011 August 1. 


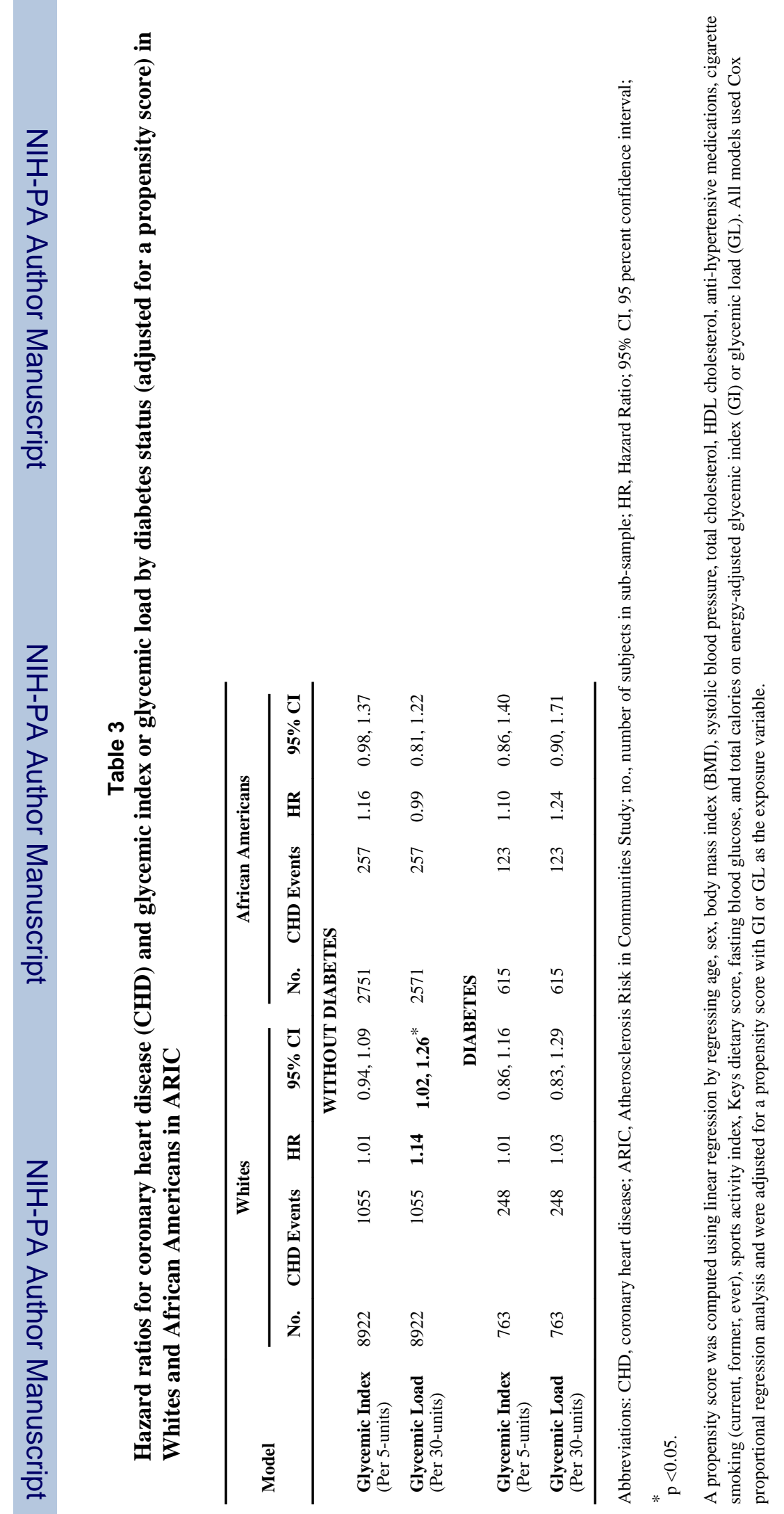

Ann Epidemiol. Author manuscript; available in PMC 2011 August 1. 